\title{
DEVELOPMENT OF SUSTAINABLE DISTRIBUTION LOGISTICS SYSTEM
}

\author{
Rolandas Drejeris, *Mindaugas Samuolaitis \\ Vytautas Magnus University, Lithuania \\ *Corresponding author's email: mindaugas.samuolaitis@vdu.lt
}

\begin{abstract}
Sustainable development is playing an increasingly important role in today's society, and it is essential for companies seeking to meet the needs of the market to pay increasing attention to the application of sustainable development principles in their operations. The enterprise logistics system is one of the essential activities ensuring the company's competitiveness, which ensures timely production and quality of customer service. However, in order to integrate the principles of sustainable development into the company's logistics system, it is necessary to develop a model that identifies the impact of sustainability on each factor of the logistics system. The paper analyses the impact of sustainable development on distribution logistics to determine which activities in distribution logistics are most responsive to sustainable development and can help determine the level of corporate sustainability. The main purpose of the model, presented in the paper, is to help the business sector integrate sustainable development principles effectively in distribution logistics, taking into account the significance of ongoing factors in the system for sustainability.
\end{abstract}

Key words: logistics system, sustainability, distribution.

\section{Introduction}

Proper management of logistics processes promotes the development of various sectors not only at regional or national level but also at international level. A responsible approach to logistics processes is a prerequisite for implementing the basic principles of sustainable development from the supplier to the end user. Process optimization and sustainable development are becoming an integral part of logistics. Responsible logistics is no longer just a term in today's society, but one of the key factors in ensuring market competitiveness.

Logistics chain management is extensively analyzed in the scientific works of foreign and Lithuanian authors; however, the creation and effective management of an offensive logistics chain is becoming increasingly important. Guidelines on how to achieve greater sustainability in order to improve economic performance are still widely debated by authors and practice-oriented minds. These guidelines could be later used by start-ups and well developed companies concerned about environmental sustainability. The absence of a universal model detailing implementation of actions directed towards sustainability of logistics processes is one of the greatest issues currently faced by both business theorists and practitioners. As mentioned above some scientific works for sustainable logistics actions exist, but methodological potential according to systematical approach is especially poor. The high demand for a solution to this problem and its practical and scientific topicality motivated us to present research into this field. The aim of the research is, firstly, to examine the relevance of sustainable logistics as a component of sustainable activity and, secondly, to present a model which would determine possible routes for implementing commonly accepted logistical actions associated with the sustainable development. The model would additionally serve as an instrument to assess the readiness and possibility to develop logistical actions in general for any logistics corporate sustainable activity.

Integrating sustainability procedures into the enterprise logistics system is an important enough factor in increasing the competitiveness of logistics enterprises. Proper management and optimization of logistics processes helps a company to compete both at national and international levels. One of the most important aspects is providing quality logistics services (Chen, Chang, \& Lai, 2009; Huang, Wang, \& Xue, 2012).

A sustainable logistics chain is understood as an activity that is consistent with the principles of sustainable development and ensures the long-term sustainability of the company. And its creation may require tangible and intangible investments.

Problem of the research. Quality of distribution system organization is an important part of the logistics chain, but as a result of sustainable business development at national and international levels, the question arises how to organize distribution logistics to meet the maximum requirements of sustainable business? The absence of an instrument for solving this task is topical for both theorists and practitioners.

Aim of the research. The aim of the paper is developing a model for sustainable distribution logistics that will help the company successfully integrate sustainability principles into distribution logistics.

Objectives of the research:

- to review the theoretical aspects of distribution logistics system and its main components,

- to analyze importance of sustainability integration in distribution logistics system,

- to create theoretical and sustainable distribution logistics model. 


\section{Materials and Methods}

The solution to this problem is complex and requires a systematic approach. A systemic approach does not mean solving all aspects of a complex problem at once, but it does allow us to see the big picture: to break it down into separate components, to analyze them, to highlight the most important, and finally to integrate them into a whole. So methods of modeling are required. To achieve the aim of the article through the analysis of researchers' opinions, it is also necessary to apply methods of assessment, systematisation, and comparison of information, to select the most important information describing the sustainability actions of logistics, to highlight the relationships between the logistic aspects of sustainability, to evaluate some processes of the logistics product in terms of sustainability, to clarify and present arguments highlighting the importance of the logistics aspect in sustainable business activity, to reject inappropriate arguments, to identify links between the arguments, and, based on the information, to form a new Model of Development for Sustainable Distribution system. Creation the new and innovative model was an aim of the article. For complete clarity operations of the model as well was necessary to reason consistency of the suggested model components and even their content. So, Thus, the operation of the model becomes completely clear to each of its possible users.

\section{Results and Discussion}

Requirement for the Model of Development for Sustainable Distribution System

When designing a model, it is necessary to identify the key components of the model and the factors that affect distribution logistics.

Various ways of optimizing logistics processes are described in the scientific literature. Price, customers demand, logistics service and sustainability (Lichocik \& Sadowski, 2013; Hadas, Stachowiak, \& Cyplik, 2014; Matwiejczuk, 2013; Pehlivanova, 2011) must be analyzed as most important aspects. These authors deal with different aspects in their work, but all these aspects influence the optimization of logistics processes in different sectors.

Optimization issues are also addressed in supply chain management. Logistics and supply chain analysis is becoming a widely accepted prerequisite for business sustainability. Bertasius (2007) presents evaluation of integrated management system, and Kaplan \& Anderson (2004) present the analysis and application of time-based management methods of enterprise performance evaluation. The presented models identify the main elements of the logistics system, but in order to develop a model for the appropriate part of the distribution logistics system, the warehousing and transportation of the finished product must be analyzed.

In the scientific literature, Stankevičiūtè \& Savanevičienè (2013) analyze the effectiveness factors of corporate social responsibility impact and their significance for modern society.

Halsan (2007) examines the main human factors that have the greatest impact on the development of corporate social responsibility in the business sector. A study by Hall, Matos, and Silvestre (2012) analyzes the need for companies to invest in a sustainable supply chain.

The authors extensively analyze the optimization of logistics processes in terms of added value, cost, quality, customer satisfaction and other factors efficiency (Lichocik \& Sadowski, 2013). It also analyzes the organization of quality services and their impact on the implementation of social responsibility objectives (Hadas, Stachowiak, \& Cyplik, 2014) and comparing the quality of logistics services provides an opportunity to improve this process (Kilibarda, Zečevic, \& Vidovic, 2012). Customer satisfaction with logistics service quality has a significant impact on the sustainability of companies (Lisinska-Kusnierz \& Gajewska, 2014).

Various models are being developed to increase the efficiency of logistics operations. One of such models is the model of logistic enterprise and sustainable development (Vasiliauskas, Zinkeviciute, \& Simonyte, 2013), which helps to better understand the influence of sustainable development on increasing the efficiency of enterprise activities. Juščius \& Jonikas (2013) in their research aimed to reveal the influence of corporate social responsibility integration on the creation of value added in companies.

Every business sector needs to be very well understood and know how to manage the logistics chain, since the quality of its processes depends on the organization's quality existence and competitiveness (Matwiejczuk, 2013; Pehlivanova, 2011, Weijers, Glockner, \& Pieters, 2012) and successful risk management (Vikulov \& Burit, 2014).

Based on the analysis of scientific literature, a model is being developed in which key elements of distribution logistics are tested through key sustainability dimensions. The purpose of the model is to help the business enterprise properly analyze, evaluate and develop a sustainable distribution logistics chain.

Creation of the Model of Development of Sustainable Distribution System

In developing a sustainable distribution logistics chain model, the key elements of distribution logistics related to warehousing and transportation are tested through sustainability dimensions to identify the level 
of sustainability and improvement potential of the company.

The presented model of the factors of sustainable distribution logistics system design the process of the distribution system in order to improve the organization of the company's logistics activities taking into account the influence of sustainability on each process factor.

The developed model analyzes the key drivers of the distribution process in order to identify opportunities for their improvement with respect to the integrity coherence. It means that mentioning all the factors and their impact to the objects is necessary. At the beginning, some constant general indicators have to be determined, then possibilities assessment for improvement logistical actions in the area of sustainability is preferable.

Systematizing the data in the first part will be used to analyze the distribution system of the companies' output and identify the opportunities for improvement, which is better to analyze further in the next part of the suggested paper. According to the mentioned ideas for model creating in the Figure 1, we present the model of Development of Sustainable Distribution system. The model of Development of Sustainable Distribution system is presented in Figure 1. Action for determination general constant indicators

In order to conduct a comprehensive analysis of the distribution system in terms of sustainability, the first step is to gather information about the elements of the enterprise distribution system. The key elements of a distribution system can be divided into two environments: storage and transportation. These environments are made up of 6 essential components that are presented in part I:

- warehousing object;

- warehousing infrastructure;

- warehousing technology;

- transportation object (cargo);

- transport infrastructure;

- vehicles.

When analyzing the storage process, it should be noted that the quantity and nature of storage factors depend on:

- the quantity of product marketed;

- storage network;

- number of intermediaries;

- storage space;

- warehousing techniques and technologies;

- customer / user type and stockpiling;

- additional services provided (sorting, packing, customs, transit, etc.)

In the storage environment, three components of the distribution system are analyzed: storage object, storage infrastructure and work organization, warehouse and technology. Warehousing object - a stock in a warehouse for sale. This object in the distribution system is affected by different factors depending on the specifics of the company and the organization of work. The information collected is required to organize the storage of the facility: cargo volume, weight, space occupied, transferability, environmental and equivalent to the adaptability of the storage environment. Storage infrastructure is necessary information to identify current and potential factors involved in the organization of the entire process. Warehouse internal infrastructure, management solutions depend on the functionality of the whole system. Information on the warehouse size, area, adaptability, layout and integrity is collected. Taking into account the infrastructural components, the work inside the warehouse is organized and the factors that take place there are identified: packaging, sorting, storage, assembly, transportation inside the warehouse, documentation, etc. Warehouse and technology - analysis of warehouse type, its applicability, geographic environment and accessibility, cargo handling technologies and warehouse management techniques and technologies.

Factors analyzed in the transport environment relate to the organization of the transport system:

- type of transport;

- stowage equipment;

- adaptability of the vehicle;

- vehicle technology and technology;

- IT related to vehicles;

- transport route, etc.

The cyclical structure of the model shows that actions of sustainability have to be permanent in any logistics company. In other parts of the paper detailed explanation of the processes for sustainability is presented.

Three components have to be analyzed in the transport environment: transport object (cargo), transport infrastructure and vehicle. Transport object (cargo) is the main element on which the choice of vehicle, adaptability of machinery, work organization and other functional elements depend. In organizing work on the subject of the shipment, consideration shall be given to pre-loading factors, loading factors, factors occurring during transport, factors occurring at unloading. The choice of vehicle and route planning, the organization of the driver's work and additional checks during cargo transportation depend on the weight and volume consistency of the object and other components. Transport infrastructure determines availability of cargo transportation, what technologies are needed, possibilities of cargo handling, suitability of communication, applicability of IT technologies, etc. 'Vehicle' means the adaptability of a vehicle to the carriage of goods, the technology and IT in-vehicle, its equivalence to the 


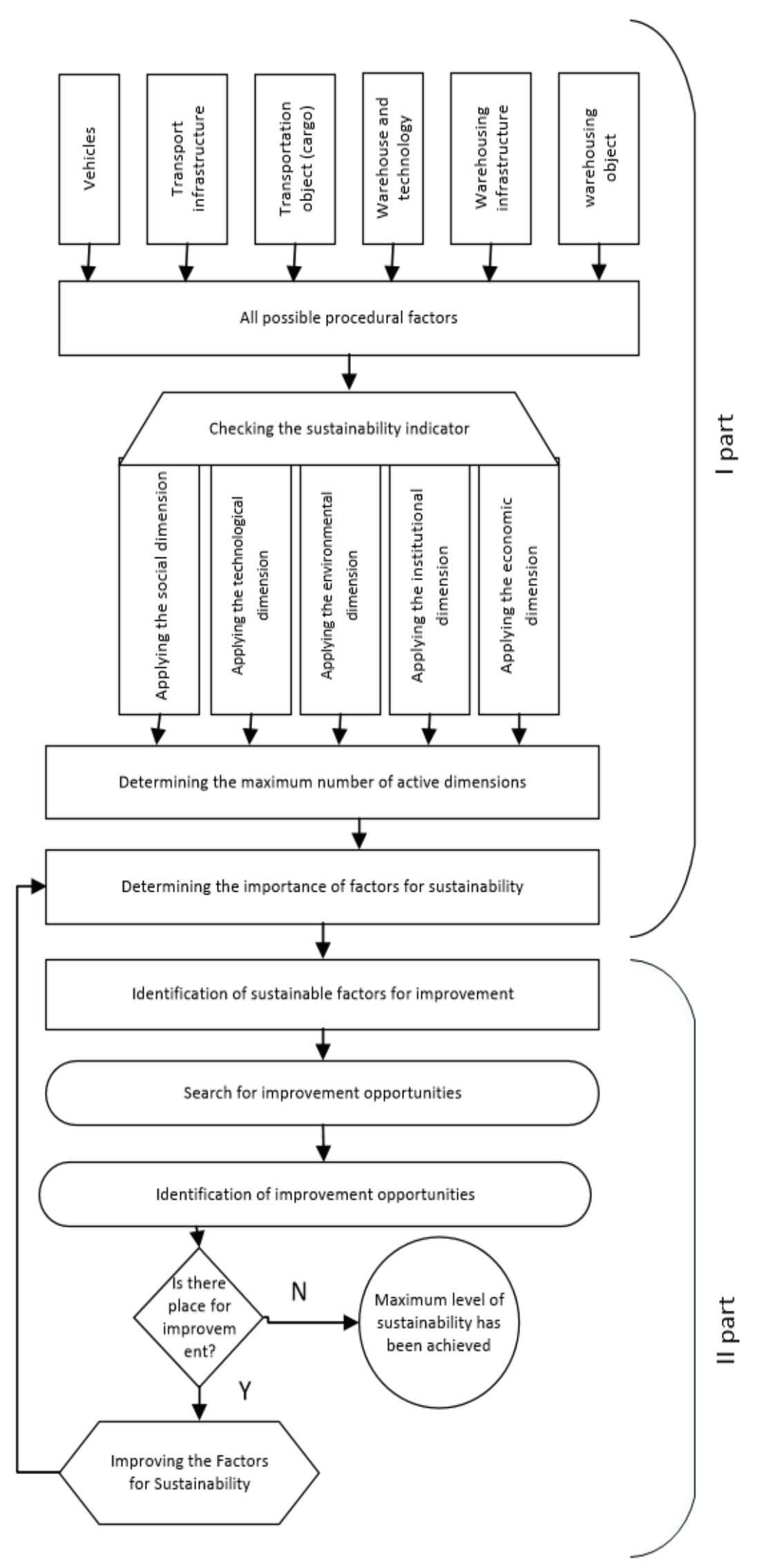

Figure 1. Model of Development for Sustainable Distribution system. 


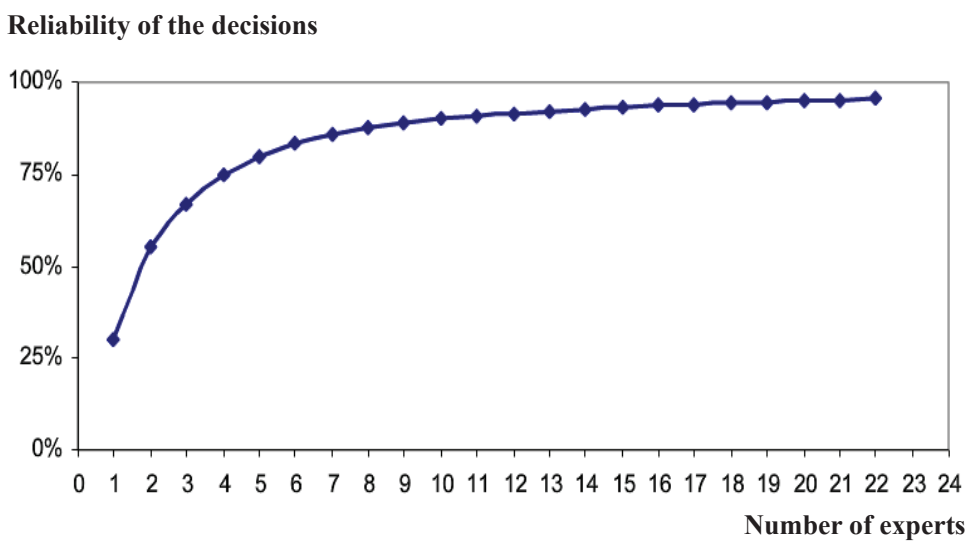

Figure 2. The decision reliability dependence on number of experts (Wright et al., 2019).

requirements of the legal environment in which the vehicle is transported.

In the first part, by analyzing the ongoing factors of all the essential components of the distribution system, a list of all possible factors is created, which is then analyzed, evaluated and refined. It should be noted that the key components of distribution logistics in the logistics process are interdependent, so it is clearly distinguished which factors are appropriate for one component and which are practically impossible for the other. Distribution logistics factors and their actions are fully integrated and function systematically. Both storage and transportation factors are determined by the object being stored and transported, so full object analysis is required to identify the specifics of work organization.

By systematizing information on procedural factors, their sustainability is scrutinized and corresponds to 5 dimensions of sustainability: social, technological, environmental, institutional and economic.

Each factor may be fully consistent and integral with all five dimensions, but may not be integral with all of them. There must be determining the maximum number of active dimensions, which identifies each factor to how many dimensions it can match. This is essential for assessing the coherence of factors. Failure to identify this figure will result in a non-validation indicator, as some factors may not be measurable due to their specificity.

After identifying the factors that are sustainable and need to be improved, it is necessary to determine the significance of the factors for sustainability and company processes. For this step, expert evaluation is used and all procedural factors are ranked according to their significance coefficients from maximum to minimum significance for coherence and for the company and a generalized list of systematic information is derived. This list is needed to implement the next steps in the process, prioritizing the steps to be taken to achieve the maximum cohesive effect within the company in the Part II of the model. Evaluation of factors in terms of sustainability

When conducting factor assessment, the factors that occur primarily within the company are categorized as cohesive and refinement factors for distribution logistics. Sustainability is determined in the context of sustainable factors. After identifying the factors to be improved, the model looks for opportunities for factor improvement and assesses the feasibility of factor improvement in the current situation, in accordance with sustainability principles.

The search for opportunities creates a list of improvement opportunities and identifies, and evaluates the improvement opportunity company based on a sustainable system of information on the significance of the factors. This is done based on the company's ability to perform improvement actions at the current situation. Significance of the factors has to be determined by expert method. Number of experts influences reliability of the final decision. We suggest using the scheme (Figure 2) for determination of the best number of experts, according to which we think that 7-8 experts are enough for a reliable decision.

Expert requirements also need to be established: logistics experience, understanding of sustainability, achievements in these areas.

Prior to their assessment, it was important to establish criteria for the assessment in order that the assessment could be as objective as possible (Drejeris $\&$ Miceikiene, 2018). To do this, we proposed a scale of 100 points and total estimates are calculated as follows (Drejeris \& Oželienè, 2019):

$$
W_{i}=\sum_{i=1}^{n} W_{i e} \quad, \overline{i=1}, \mathrm{~m}
$$

where Wie is an estimate of the i-th question by the e-th expert, $\mathrm{n}$ is the number of experts and $W i$ is the sum of all i question estimates by all experts.

The equation below is used to establish the relative importance of the criteria (Drejeris \& Oželienè, 2019): 


$$
n_{i}=\frac{W_{i}}{\sum_{i=1}^{m} W_{i}}, i=\overline{1, m},
$$

In this case the sum of criteria importance will always equal one:

$$
\sum_{i=1}^{m} n_{i}=1
$$

If the result is different, there must be a calculation error.

The results of the experts' assessment are better to present in the form of table.

Then, the assessment of factors' value according to possibilities for sustainability has to be calculated by the following formula (Drejeris \& Oželienè, 2020):

$$
T=\sum_{i=1}^{j} \eta_{i} K_{i j}
$$

Where $T$ - total value of factors according to possibilities to be sustainable, $K$ - value of every factor in a 10-point system.

Once the potential for improvement is identified, improvement of the identified factors in terms of sustainability is initiated. After completing the improvement procedures, the process goes back to the beginning of the second part to determine the level of sustainability of the company.

If there is no way for improvement in the current situation, then maximum level of sustainability has been achieved.

The whole model is created to help business to identify current situation of sustainability of distribution logistics and how to manage improvement of it.

\section{Conclusions}

1. Distribution logistics management is one of the core activities of a company to increase its competitiveness. Improper distribution of the logistics chain management can cause the company to suffer both financial and customer losses. The qualitative aspect of distribution logistics is extensively analyzed in the scientific literature, but in order to ensure the quality, increasing attention is paid to the sustainability of factors.

2. Distribution logistics chain management sustainability is most clearly seen and analyzed by customers. Distribution logistics activities are carried out up to the customer, and as the impact of sustainability in today's society becomes one of the customer's evaluation criteria, the increasing influence on the competitiveness of the company derives from its ability to deliver sustainable distribution logistics.

3. The developed theoretical model of sustainable distribution logistics is designed for selfassessment and development of regular distribution logistics. For the fully functioning model, it is necessary to conduct a sustainability assessment of all distribution logistics factors and identify opportunities for their improvement. Emerging scholarly topic is discussed in a carefully crafted and persuasively argued position before active experimentation and other forms of empirical assessment. Thus, our further research will focus on the application of the proposed model in various industrial sectors.

\section{References}

Bertasius, D. (2007). Evaluation of the Industrial Enterprises Management Systems Effectiveness. Technological and Economic Development of Economy, 13(1), 3-9.

Chen, K., Chang, C., \& Lai, C. (2009). Service quality gaps of business customers in the shipping industry. Transportation Research Part E, 45, 222-237.

Drejeris, R., \& Miceikiene, A. (2018). Multi-Criteria Measurement of sustainable innovativeness in farming organisations: evidence from Lithuania. Sustainability. Vol. 10, No. 9, pp. 33-47.

Drejeris, R., \& Oželiene, D. (2019). Modeling environmental actions of corporate sustainable activity: evidence from Lithuania. Central European business review. Vol. 8, No. 5, pp. 68-93.

Hadas, L., Stachowiak, A., \& Cyplik, P. (2014). Production-logistic system in the aspect of strategies for production planning and control and for logistic customer service. LogForum.

Hall, J., Matos, S., \& Silvestre, B. (2012). Understanding why firms should invest in sustainable supply chains: a complexity approach. International Journal of Production Research. Vol. 50, No. 5, 1 March 2012, pp. 1332-1348. ISSN 0020-7543 print/ISSN 1366-588X online.

Halsan, A. (2007). Human resource development and organizational values. Journal of European Industrial Training, 31(6), 435-448.

Huang, B., Wang, T., \& Xue, X. (2012). Service-selecting approach based on domain-specified 'Quality of Service' model and its application in logistics. The Service Industries Journal, 32 (9), 1571-1588.

Juščius, V., \& Jonikas, D. (2013). Integration of CSR into Value Creation Chain: Conceptual Framework. Inžinerinè ekonomika, 24(1), pp. 63-70. 
Kaplan, R.S., \& Anderson, S.R. (2004). Time-based activity-based costing. Harvard Review, 131-138.

Lichocik, G., \& Sadowski, A. (2013). Efficiency of supply chain management. Strategic and operational approach. Scientific Journal of Logistics. LogForum 9 (2), pp. 119-125. ISSN 1895-2038.

Lisinska-Kusnierz, M., \& Gajewska, M. (2014). Customer satisfaction with the quality of the logistic services. Scientific Journal of Logistic. LogForum 10 (1), pp. 13-19. ISSN 1895-2038.

Matwiejczuk, R. (2013). Logistic potentials in business competitive advantage creation. Scientific Journal of Logistic. LogForum 9 (4), pp. 265-275. ISSN 1895-2038.

Pehlivanova, T. (2011). Optimization of management of logistic systems in agriculture. Trakia Journal of Sciences, Vol. 9, No. 4, pp. 16-19. ISSN 1313-7069.

Stankevičiūtè, Ž., \& Savanevičienè, A. (2013). Sustainability as a concept for human resource management. Ekonomika ir vadyba- Ekonomics and management (2), pp. 837-846. ISSN 2029-9338.

Vasiliauskas, A.V., Zinkeviciute, V., \& Simonyte, E. (2013). Implementation of the concept of green logistics referring to it applications for road freight transport enterprises. Business: theory and practice. 14 (1), pp. 43-50. DOI: 10.3846/btp.2013.05.

Wright, G., Cairns, G., O’Brien, F., \& Goodwin, P. (2019). Scenario analysis to support decision making in addressing wicked problems: Pitfalls and potential. European Journal of Operational Research. 278(1), pp. 3-19.

Weijers, S., Glockner, H., \& Pieters, R. (2012). Logistic service providers and sustainable physical distribution. Scientific Journal of Logistic. LogForum 8 (2), pp. 157-165. ISSN 1895-2038.

Vikulov, V., \& Burit, A. (2014). Risk assessment and management logistics chains. Scientific Journal of Logistic. LogForum 10 (1), pp. 43-49. ISSN 1895-2038. 